\title{
Students' Perception Of Homework Assignments And What Influences Their Ideas
}

Denise Letterman, Ph.D., Robert Morris University, USA

\begin{abstract}
Authors have researched the effects of homework, but few studies have delved into the idea of students' attitude towards homework. Consequently, students' perception of homework, the principal participants, remains largely unknown. Students' experience in homework that started as early as elementary school has influenced their ideas of homework. Trying to get students to complete their homework is one of the most frequent and frustrating behavior problems for educators. The purpose of this study is to understand students' perception of homework assignments and identify factors that influenced their ideas. The participants for this research project were 180 undergraduate students enrolled in select Principles of Finance and Corporate Finance classes (encompassing three semesters and nine classes) at Robert Morris University, Pittsburgh, Pennsylvania. Results of the study summarize students' opinions of homework assignments while in high school, college, and for the specific course in which the questionnaire was administered. Tests of significance revealed seven (of the nine classes) significant differences between the actual number of times homework was handed in and the pre-conceived number of times students estimated homework assignments would be completed on time.
\end{abstract}

Keywords: Homework; Student Perception

\section{INTRODUCTION}

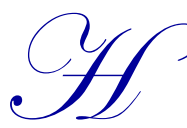

omework has always been a source of controversy among students, parents, and educators. Homework issues center around quantity, quality, and time restrictions on out-of-class activities. Cooper (1989) defined homework as work assigned by educators for students to carry out during nonschool hours. When educators assign homework, they need to take into consideration student ability level and how after-class activities impact student performance (Cooper, 2001). Ultimately it is the student that must use his/her own discretion about whether, when, and how to complete homework assignments.

Researchers have studied the effects of homework. The correlation between homework completion and student achievement has been debated. The questions pertaining to how much homework is beneficial and whether parental involvement helps students develop better study habits has been examined. However the concerns of the students, the principal participants, remain largely unknown. Homework is usually assigned with the best of intentions by educators but may cause conflict between school and home. The purposes and benefits of assigning homework may lack shared agreement between parents, students, and educators. There is extensive research literature on parental beliefs and involvement in homework at the primary educational level. However, there has been less research on how students view the purpose and benefits of homework. Views on homework vary according to the type of activity and to its purpose (Bryan, Burstein, \& Bryan, 2001). Somewhere between elementary and junior high school, ideas about homework and the dynamics of homework practices change significantly (Cooper, Lindsay, \& Nye, 2000). Reasons usually quoted by educators for assigning homework include: to help students practice skills or prepare for exams; to help students develop good work habits; to develop life skills; to develop critical thinking; and to motivate students to learn (Metropolitan Life Insurance Company, 2007). 
While these reasons for assigning homework are well-intended, they reflect the view point of educators. Difficulties in achieving these goals may be caused by differences in student perception of the purpose for homework assignments. Even in a generally supportive environment, students may perceive a substantial cost to be associated with homework. It may restrict time available for sports, extracurricular or leisure activities, required too much time or effort, or simply conflict with family responsibilities. Consequently, the decision to spend time on homework may carry high opportunity costs as other more desirable activities are foregone.

Student motivation to complete homework assignments is influenced by a collection of beliefs, attitudes, and emotions. These include students' experiences that lead to success or failure, their personal expectations and standards for performance, and confidence in their ability to do well. These beliefs, attitudes, and emotions develop in the multiple contexts of students' homes, schools, and culture. Parents' and educators' beliefs about learning have a profound influence on the development of student's own beliefs as to what it takes to do well in school and the efforts necessary to learn.

The purpose of this paper is to examine students' perception of homework assignments and to identify factors that might influence their ideas. The study looks at how students perceive homework as an important part of their school experience and identifies any significant differences between the actual number of times students handed in homework and the pre-conceived number of times students estimated homework assignments would be completed on time.

\section{REVIEW OF LITERATURE}

The educator's role in assigning homework should be obvious, but do most educators consider the idea that students view the task as important when it is assigned?

A study conducted by Yazzie-Mints (2006) polled over 81,000 students about their overall perception of their high-school experience. A section of the survey was devoted to students' perception of homework. The study found that 'Doing Written Homework' was among the most important activities to students. Students were also asked about how many hours per week they spent doing written homework. Forty-three percent of students reported spending one hour or less each week on written homework. The researcher also reported that on average only seven percent of participants felt homework to be 'Not at All' important while 68 percent felt it was either 'Somewhat Important' or 'Very Important'.

Researchers at UCLA have been conducting an annual survey for college freshman nationwide since 1966. In the first year of the survey, 47 percent of respondents reported that they spent more than five hours per week studying or doing homework during their senior year of high school. That figure has dropped every year since then hitting a low of 34 percent in 2002 (Sax et al., 2002). That means 67 percent of college-bound high school seniors have no more than one hour of homework per night and none on weekends. In addition about 25 percent of college freshman said they spent more than five hours per week partying or watching television as high school seniors. The study also revealed that at the same time students are reporting record lows in the amount of homework given in high school, they are reporting record grade point averages with 46 percent of college freshman graduating from high school with an A average.

Metropolitan Life Insurance Company (MetLife, 2007) conducted an online survey to more than 2,000 students' grades 3 through 12 asking whether homework helps them learn more and its overall importance. The poll uncovered widespread support for homework showing 77 percent of students (and 80 percent of educators and parents) said homework is important or very important. However when asked if doing homework helps them learn more in school, only 69 percent of students agreed. The study also found that 75 percent of students polled felt they had enough time to do all of their homework including 69 percent of secondary school students. However, it was reported that only 69 percent of those students said they almost always had their homework finished.

The relationship between homework and student achievement has been debated. A study conducted by Cooper (2001) looked at this relationship with elementary and secondary school students. The results showed the relationship between homework and achievement seems to be different at various grade levels. The research 
involving thousands of students shows little correlation between homework and test scores in elementary school, but the relationship becomes positive in secondary school. Cooper goes on to hypothesize that a student's attitude toward homework could be predicted by how much homework they completed, by student ability, and by parent involvement.

Research suggests that homework completed with a family member is associated with better academic performance (MetLife, 2007). A study conducted by Leons and Richards (1989) of 401 public school students in grades 5 through 9 reported significant findings in academic performance regarding family involvement with homework.

Many educators are likely to accept the notion that students' willingness to work in a particular course is based in large part on the desired final grade. Results from a study by Lammers et al. (2005) suggest that there is surprising agreement between faculty members and students on the amount of work required for success in university courses. The same study also suggests that student's perceptions regarding study time per week exceeded what faculty members considered necessary for success in university courses.

Although the primary goal of homework is to provide independent practice for students to internalize content and processes, it also can strengthen the relationship between home and school through providing parents the opportunity to work with their children to develop better academic study skills (Gill \& Schlossman, 2003). Homework plays a part in establishing a student's beliefs and study patterns regarding academic work. It can be argued that the elementary years are especially critical when shaping student perceptions (Coutts, 2004).

Parental involvement with homework is of theoretical and practical interest. Some researchers and educators believe it is a key ingredient in the development of beliefs and attitudes that help to foster academic achievement (Bempechat, 2004). However, researchers and educators are split about the extent to which parents should be involved in homework completion (Cooper, 2001) and it remains unclear whether parental involvement is positively related to student achievement.

\section{HYPOTHESIS / RESEARCH OBJECTIVE}

Educators believe the theory behind homework is to further student knowledge outside the classroom by assigning work after an independent level of understanding has been achieved.

Literature suggests there is a relationship between homework and student achievement and students do recognize that doing homework is one of the most important activities while in school. But do students actually complete their homework assignments? The purpose of this paper was to identify students' perception of homework assignments as well as to determine if there is a difference between actual and estimated number of times homework problems are completed by students. The impact of including homework as part of the students' course grade is also examined.

To test this research hypothesis, the following null hypotheses was used:

$\mathbf{H}_{\mathbf{0}}$ : Making homework a part of a student's grade will not increase the likelihood that students will complete more homework assignments.

The hypothesis is expected to be rejected.

\section{METHODOLOGY}

Data collected by means of a questionnaire expanded over three semesters. The two courses chosen for the study were Principles of Finance (FINA3000) and Corporate Finance (FINA3200). The Principles of Finance course is required for all students enrolled in the School of Business at Robert Morris University. Students enrolled in the School of Engineering, Mathematics, and Science can take the course as an elective. The Corporate Finance course is required for finance majors (School of Business) and actuary science majors (School of Engineering, 
Mathematics, and Science). Students declaring other majors within those two schools can take Corporate Finance as an elective. Three Principles of Finance classes and six Corporate Finance classes were included in this study.

During the first class of each semester, the syllabus was reviewed which included chapters to be covered and corresponding homework problems. The number of problems for each chapter ranged from 1 problem to 13 problems. After reviewing the syllabus, students were given a survey to be completed in class that listed the chapters as well as the number of homework problems for each chapter. Students were asked to estimate the number of homework problems they expected to have completed on time from each chapter.

In addition, each student attending the above mentioned classes received a questionnaire after the first exam to be completed in class. Students enrolled in the Corporate Finance class that had already completed the questionnaire in the Principles of Finance class did not receive another questionnaire in the corporate class. The questionnaire took approximately 10 minutes to complete and was constructed to give students limited alternative responses to each question.

The purpose of the questionnaire was to gain insights into student perception of homework assignments. The first part of the questionnaire pertained to general demographics. The second part asked questions pertaining to students experiences of homework assignments from high school and college classes in general. The third part asked questions pertaining to homework assignments for the specific course in which the questionnaire was administered.

There were 61 questionnaires handed out in the Principles of Finance classes in which 3 were not usable because the questionnaire was not completed. In the Corporate Finance classes, 124 questionnaires were handed out in which 2 were not usable for the same reason. The questionnaires were kept completely anonymous to eliminate any bias that may occur if the respondents were to identify themselves.

A sample of the questions used in the study is available in Table 3. The results were coded using standard coding procedures with modified Likert scales for questions related to homework experiences at both the high school and college level (Table 3, Part II). Table 3, Part III shows results from questions pertaining to homework experience specific to the course in which the questionnaire was administered. Descriptive statistic and tests for significance results from the study were determined using SPSS.

\section{DEMOGRAPHICS}

Table 1 shows the detailed results of the demographics section of the questionnaire. A summary of the main points revealed the following characteristics:

- $\quad$ The Principles of Finance classes comprised 39.7 percent females and 60.3percent males of the respondents while the Corporate Finance classes comprised 25.4 percent females and 74.6 percent males.

- Students from the principles classes majoring in finance, accounting, economics, actuary science, or finite math represented 51.7 percent of the respondents while students from the corporate classes declaring the same majors comprised 97.5 percent of the respondents.

- $\quad$ The average number of hours worked per week for students in the Principles of Finance classes was 19.8 hours and 16.1 hours for students in the Corporate Finance classes.

- $\quad$ Students enrolled in the Principles of Finance classes indicated 29.3 percent of their mothers and 31 percent of their fathers earned a Bachelor's Degree or higher. Students from the Corporate Finance classes indicated 45.1 percent of their mothers and 43.4 percent of their fathers earned a Bachelor's Degree or higher.

\section{FINDINGS}

Homework is a form of student independent practice of material covered in class. Its positive effects on learning have been studied. When homework is aligned with classroom work and when educators provide verbal or written praise on homework completion, students become more motived to complete the assignments (Silverman \& 
Casazze, 2000; Hancock, 2000). The present study showed about half of the students in both the Principles of Finance and Corporate Finance classes agreed that instructor recognition of doing a good job on homework assignments was important to them (Table 3, Part III, Q8).

While research is unclear as to the benefits of parental involvement associated with the completion of homework, the study by MetLife (2007) found that parental involvement impacts student academic performance. As part of the questionnaire, students were asked if parents/spouse asked about homework. The respondents indicated that at the high school level, about 61 percent of the parents did ask about homework but that percentage fell to 27.6 percent for students taking the Principles of Finance classes and only 20.5 percent in the corporate classes. The study suggests as students continue their education through college, parental interest in homework assignments decreases.

The length of the homework assignments as well as time permitted to complete such assignments effect student motivation to complete homework. A study conducted by Trautwein, Killer, Schmitz, and Baumert (2002) found that extensive homework assignments were associated with a comparatively unfavorable development in overall student achievement. The results from the present study found that 41.4 percent of students in the principles classes and 53.3 percent of students enrolled in the corporate classes felt homework assignments in college were too long. This is a higher percentage than students experienced from high school homework assignments (Table 3, Part II, Q7). However, when the students were asked if they felt they had sufficient time to complete homework assignments for the specific course in which the questionnaire was administered, approximately 86 percent of the students in all classes agreed or strongly agreed. These findings are in agreement with the MetLife (2007) study in which 75 percent of students polled felt they had enough time to complete homework.

Students experience with homework plays an integral part of laying the foundation for a student's career in learning (Coutts 2004). Students' goals as well as the value, meaning, and significance they attach to the homework activities are critical for the choices the students make, the effort they will contribute to the assignment, the persistence in accomplishing homework assignments, or whether to do homework at all. From the students' perception, the choice of completing homework has certain costs and benefits. Students who perceive homework assignments as having little intrinsic value or as 'busy work' will view homework as having greater costs than benefits and therefore will choose not to complete the assignment. Based on the student responses to the questionnaire, approximately 68 percent of the students in all classes felt homework was just "busy work" in high school. Fortunately that perception dropped to about 19 percent at the college level (Table 3, Part II, Q9). Students also felt there was a higher intrinsic value associated with homework assignments at the college level by indicating that approximately 80 percent of the respondents felt homework assignments were necessary to understand the course material at the college level (Table 3, Part II, Q1; and Part III, Q12). The findings indicate that students recognize the importance of homework assignments in understanding course material which is in line with Coopers (2001) study that found a strong relationship between homework and student achievement at the secondary school level.

Students were asked about the level of difficulty of the homework assignments for the specific class in which the questionnaire was administered and if students asked for help if they didn't understand an assignment (Table 3, Part III, Q3 and Q7). Only 10.4 percent of the students from the principles classes and 20.6 percent from the corporate classes felt homework was too difficult. For those students experiencing difficulty, about half indicated they asked the instructor for help.

The findings of the present study agree with other studies in that students acknowledge the importance of homework assignments. However, trying to get students to complete those homework assignments is one of the most frequent and frustrating behavior problems for educators. Tests of significance were used to identify significant differences between the actual number of homework problems completed and what students estimated they would have completed when homework was due (Table 2). The results showed that in seven of the nine classes, significant differences were found between the actual number of homework problems completed by students and estimated homework problems to be completed when collected as determined by students at the beginning of the semester. In six of the classes in which significant differences were determined, students completed fewer problems than originally indicated. This outcome also conflicts with the questionnaire response (Table 3, Part II, Q13) that 
asked if homework assignments were completed on time. Student response to this question indicated 79.3 percent of Principles of Finance students and 79.5 percent of Corporate Finance students either agreed or strongly agreed that homework was completed on time at the college level.

Based on the questionnaire responses (Table 3, Part II, Q12) 50 percent of students enrolled in the Principles of Finance classes and 59.8 percent of students from the Corporate Finance classes felt homework should be included as part of a student's course grade. Students indicated a stronger support for this at the high school level possibly because in high school students indicated homework was already included as part of a student's course grade (Table 3, Part II, Q4).

In addition, the results (tests of significance) found in Table 2 showed that when homework becomes a larger part of a student's course grade, it does make a difference in homework completion. Students enrolled in the Principles of Finance and Corporate Finance classes could earn bonus points during the semester by having homework completed when due and by participating in class. These bonus points were added to a student's average course grade at the end of the semester. Students earning the maximum percentage in bonus points realized an increase in their course grade by one letter. For students enrolled in the spring 2012 classes, the maximum percentage of bonus points a student could earn increased by 4 percent. During this semester, two of the three classes showed students actually completed more homework than was originally indicated by the students with the biggest difference occurring in the Principles of Finance course.

The study showed that by increasing the percentage of bonus points that students could earn during the semester, in which homework is considered, there was an increase in the actual number of times homework was completed when due and the null hypothesis should be rejected.

Student perception of late homework assignments produced an interesting finding in that 20 percent of the respondents felt late homework assignments should be accepted for full credit (Table 3, Part III, Q10).

The most surprising student response from the questionnaire came from the question that asked if homework was based on information learned in a previous course (Table 3, Part III, Q2). Only 27.6 percent of the students in the principles classes and 44.3 percent of students from the corporate classes agreed. Why this is so surprising is that a large part of the material covered in the principle's course is based on accounting techniques as well as concepts covered in various math courses that are prerequisite courses. The corporate class is an extension of the principles class.

\section{CONCLUSION}

Although the sample size of this study was small, the effects found are meaningful. In summary, students view completion of homework as an important task and recognize the importance of homework assignments if it is appropriate and meaningful. They view homework assignments that have a higher intrinsic value beneficial in understanding course material. However, student perception of homework assignments in high school as "busy work" creates a negative connotation for such homework assignments as incoming college freshman.

Students felt they had sufficient time to complete homework assignments even though the average number of hours students worked per week was approximately 20 hours. Homework assignments for the class in which the questionnaire was administered were viewed as not being too long or difficult and educator praise for doing a good job on homework assignments was important to students.

Finally, students felt homework should be included as part of their course grade which was confirmed by the study when bonus points, in which homework completion represents a large portion of those points, was increased from 6 percent to 10 percent. The Principles of Finance class showed a larger increase in homework completion when due which is the class that contains a wider variety of business majors and the class that previously students normally did not have homework completed. 


\section{AUTHOR INFORMATION}

Denise Letterman, Ph.D., Robert Morris University, 6001 University Blvd., 211 Massey Hall, Moon Township, PA 15108, USA. E-mail: letterman@rmu.edu

\section{REFERENCES}

1. Bempechat, J. (2004). The Motivational Benefits of Homework: A Social-Cognitive Perspective. Theory Into Practice, 43, 189-196.

2. Bryan, T., Burstein, K., \& Bryan, J. (2001). Homework problems and Promising Practices. Educational Psychologist, 36, 167-180.

3. Cooper, H. (1989). Synthesis of Research on Homework. Educational Leadership, 47(3), 85-91.

4. Cooper, H. (2001). The Battle over Homework: An administrator's Guide to Setting Sound and Effective Policies $\left(2^{\text {nd }}\right.$ ed.) Thousand Oaks, CA: Corwin Press.

5. Cooper, H., Lindsay, J.J., \& Nye, B. (2000). How Student, Family, and Parenting Style Differences Relate to the Homework Process. Contemporary Educational Psychology, 25(4), 64-87.

6. Coutts, P.M. (2004). Meanings of Homework and Implications for Practice. Theory Into Practice, 43 (3), 182-188.

7. Gill, B., \& Schlossman, S. (2003) Parents and the Politics of Homework: Some Historical Perspectives. Teachers' College Record, 105 (5), 846-871.

8. Hancock, D.R. (2000) The Impact of Verbal Praise on College Students' Time Spent on Homework. Journal of Educational Research, 93, 6, 384-389.

9. Lammers, H., Kiesler, T., Curren, M., Cours, D., \& Connett, B. (2005). How Hard do I Have to Work? Student and Faculty Expectations Regarding University Work. Journal of Education for Business, 80 (4), 210-213.

10. Leone, C.M., \& Richards, M.H. (1989). Classwork and Homework in Early Adolescence: The Ecology of Achievement. Journal of Youth and Adolescence, 18 (6), 531-548.

11. Metropolitan Life Insurance Company. (2007). MetLife Survey of the American Teacher: The Homework Experience. A Survey of Students, Teachers, and Parents. New York: Author.

12. Sax, L., Lindholm, J.A., Astin, A.W., Korn, W.S., \& Mahoney, K.M. (2002). The American Freshman: National Norms for Fall 2002. Higher Education Research Institute, UCLA

13. Silverman, S.L. and Casazza, M.E. (2000) Learning and Development. San Francisco, Calif: Jossey-Bass

14. Trautwein, U., Koller, O., Schmitz, B., \& Baumert, J. (2002). Do Homework Assignments Enhance Achievement? A Multilevel Analysis of $7^{\text {th }}$ Grade Mathematics. Contemporary Educational Psychology, 27, 26-50

15. Yazzie-Mints, E. (2006). Voices of Student Engagement: A Report on the 2006 High School Survey of Student Engagement. Bloomington, IN: Center for Evaluation and Education Policy, Indiana University. 
Table 1: Demographics

\begin{tabular}{|c|c|c|}
\hline \multirow[b]{2}{*}{ Variables } & \multicolumn{2}{|c|}{ Percent of Respondents } \\
\hline & Principles & Corporate \\
\hline \multicolumn{3}{|l|}{ Gender: } \\
\hline Female & $39.70 \%$ & $25.40 \%$ \\
\hline Male & $60.30 \%$ & $74.60 \%$ \\
\hline \multicolumn{3}{|l|}{ Major: } \\
\hline Finance, Accounting, Economics, Actuary Science, Finite Math & $51.70 \%$ & $97.50 \%$ \\
\hline Management, Marketing, Business Education & $48.30 \%$ & $2.50 \%$ \\
\hline \multicolumn{3}{|l|}{ Marital Status: } \\
\hline Single & $98.30 \%$ & $95.10 \%$ \\
\hline Married & $1.70 \%$ & $4.90 \%$ \\
\hline \multicolumn{3}{|l|}{ Number of Children: } \\
\hline 1 child & $1.70 \%$ & $3.30 \%$ \\
\hline 2 children & $1.70 \%$ & 0 \\
\hline \multicolumn{3}{|l|}{ Average Hours Worked Per Week: } \\
\hline 0 hours & $17.20 \%$ & $25.40 \%$ \\
\hline $1-5$ hours & $1.70 \%$ & $3.30 \%$ \\
\hline $6-10$ hours & $6.90 \%$ & $13.90 \%$ \\
\hline 11-15 hours & $6.90 \%$ & $12.30 \%$ \\
\hline 16-20 hours & $20.70 \%$ & $12.30 \%$ \\
\hline $21-25$ hours & $13.80 \%$ & $13.10 \%$ \\
\hline 26-30 hours & $19.00 \%$ & $8.20 \%$ \\
\hline 31-35 hours & $3.50 \%$ & $3.30 \%$ \\
\hline $36-40$ hours & $10.30 \%$ & $6.60 \%$ \\
\hline$>40$ hours & 0 & $1.60 \%$ \\
\hline Average & 19.8 hours & 16.11 hours \\
\hline \multicolumn{3}{|l|}{ Highest Degree/Education Earned by Mother / Father } \\
\hline No Degree & $1.7 \% / 1.7 \%$ & $2.5 \% / 5.7 \%$ \\
\hline High School Diploma & $46.5 \% / 51.7 \%$ & $33.6 \% / 32.8 \%$ \\
\hline Some College & $3.5 \% / 3.5 \%$ & $4.9 \% / 7.4 \%$ \\
\hline Associates Degree & $19 \% / 12.1 \%$ & $13.9 \% / 10.7 \%$ \\
\hline Bachelor Degree & $20.7 \% / 17.2 \%$ & $36.1 \% / 33 / 6 \%$ \\
\hline Advanced Degree & $8.6 \% / 13.8 \%$ & $9 \% / 9.8 \%$ \\
\hline
\end{tabular}

NOTE: "Principles" represents the information from the Principles of Finance classes and "Corporate" represents the information from the Corporate Finance classes. 
Table 2: Actual Number Of Problems Completed And Estimated Number

\begin{tabular}{|c|c|c|c|c|c|c|}
\hline Semester / Class & \multicolumn{2}{|c|}{ Actual Completion } & \multicolumn{2}{|c|}{ Estimated Completion } & \\
\hline & Mean & Std Deviation & Mean & Std Deviation & t-value & p-value \\
\hline Spring 2011: Principles & 0.48 & 2.04 & 0.67 & 1.42 & -1.01 & 0.3140 \\
\hline Spring 2011: Corporate 1 & 5.44 & 7.7 & 7.75 & 10.15 & -3.61 & $0.0000 *$ \\
\hline Spring 2011: Corporate 2 & 0.85 & 1.72 & 1.32 & 2.88 & -2.88 & 0.0039 \\
\hline Fall 2011: Principles & 1.06 & 2.01 & 1.64 & 2.63 & -3.4 & 0.0000 \\
\hline Fall 2011: Corporate 1 & 1.34 & 2.21 & 2.81 & 2.56 & -7.18 & 0.0000 \\
\hline Fall 2011: Corporate 2 & 2.47 & 5.05 & 4.82 & 7.84 & -5.27 & 0.0000 \\
\hline Spring 2012: Principles & 9.66 & 6.62 & 7.4 & 6.57 & 4.58 & 0.0000 \\
\hline Spring 2012: Corporate 1 & 0.95 & 1.21 & 1.11 & 2.09 & -4.03 & 0.0098 \\
\hline Spring 2012: Corporate 2 & 10.91 & 8.92 & 10.61 & 10.21 & 0.47 & 0.6400 \\
\hline & & & & & & \\
\hline
\end{tabular}

NOTE: Means and Standard Deviations were based on the actual number of problems completed for chapters homework was collected and the pre-conceived number of problems students said they would complete for that chapter at the beginning of the semester.

Homework was a part of bonus points that students could earn over the semester. These were expressed as a percent and added to a student's average exam score at the end of the semester. For the Spring 2011 and Fall 2011 semesters, the maximum percent was 6\%. For the Spring 2012 semester, the maximum percent was $10 \%$.

* Significant at $\alpha=.05$ 
Table 3: Select Questions Taken From The Questionnaire

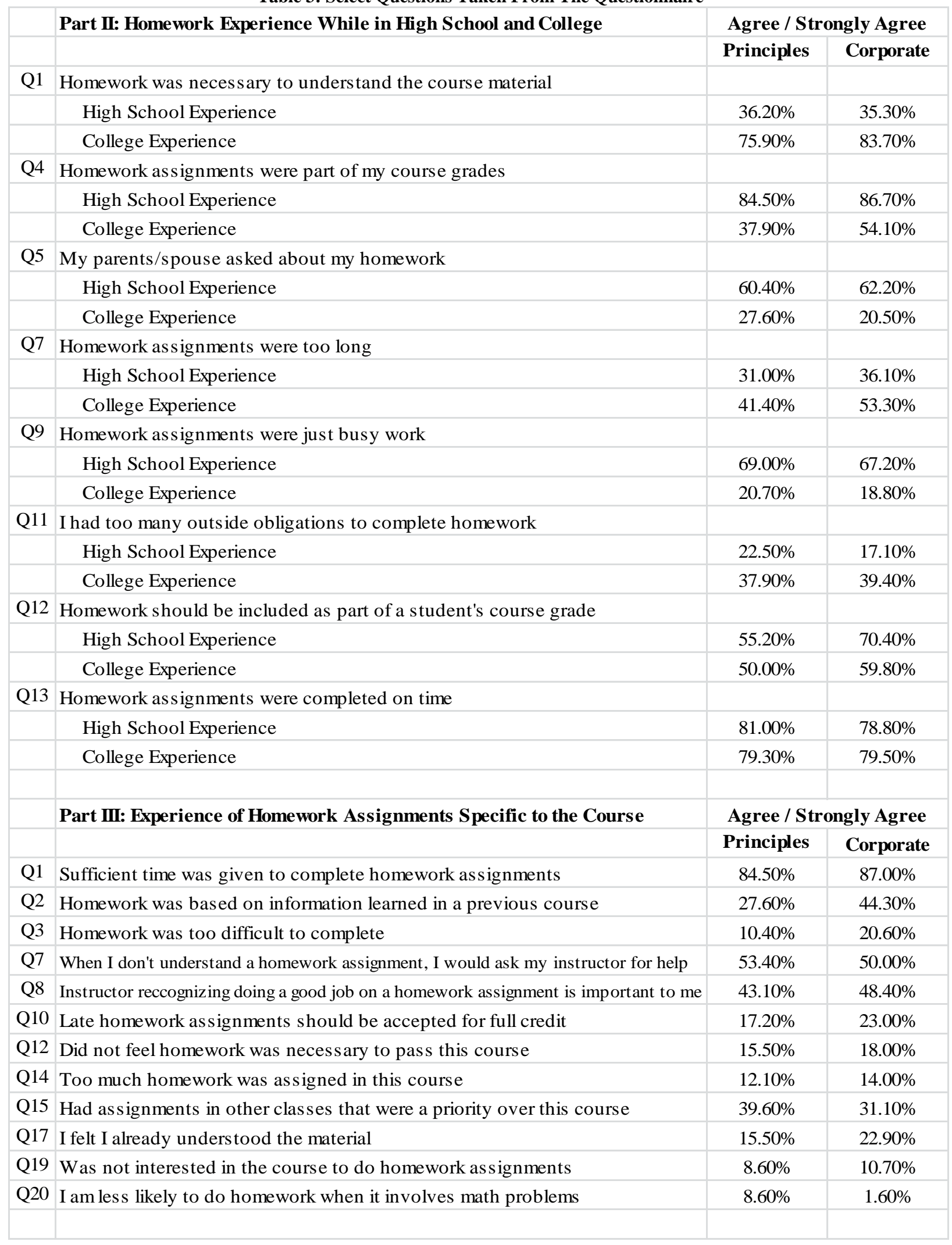

